\title{
Normative data on snoring: a comparison between younger and older adults
}

\author{
R.A. Stoohs*,**, H-C. Blum*, M. Haselhorst**, H.W. Duchna+, C. Guilleminault**, \\ W.C. Dement**
}

Normative data on snoring: a comparison between younger and older adults. R.A. Stoohs, $H-C$. Blum, M. Haselhorst, H.W. Duchna, C. Guilleminault, W.C. Dement. @ERS Journals Ltd 1998. ABSTRACT: Snoring is a common sleep-related behaviour. Increased body mass index (BMI), cranio-facial anatomical features, and older age have been linked to the occurrence of snoring. While mostly middle-aged populations have been studied for the occurrence of snoring and sleep-related breathing abnormality, this study was designed to assess the subjective report of snoring and the objective measurement of snoring at the two extremes of human age.

The study design called for measurement of snoring in two age groups (college students; $n=155$ and older subjects; mean age 64.1 yrs $n=134$ ) with a mean age difference of 45 yrs. Snoring was assessed with a validated recording device. A validated questionnaire was used to subjectively assess snoring and obtain relevant sleeprelated information.

Students and older subjects differed in the self-report of snoring. While $83 \%$ of students reported "never" or "rarely" snoring only $35 \%$ of older subjects fell into these categories. Measurement of snoring during sleep revealed that students spent more time during sleep with continuous snoring than older subjects. In older subjects, a reduction in continuous snoring was accompanied by an increase in apnoeic snoring. Subjective snoring frequency correlated with continuous snoring in students only. A positive family history of snoring increased the odds ratio for self-reported snoring but not for recorded snoring.

It has been shown that snoring frequency can vary depending on age and that the congruency between perceived snoring frequency and recorded snoring is influenced by the age of an individual.

Eur Respir J 1998; 11: 451-457.

Snoring during sleep is caused by the vibration of soft tissue in the upper airways involving anatomical structures such as the soft palate, uvula, and the pharynx [1].

Over the years snoring has become a focus in sleepdisorder medicine and research. Undoubtedly, snoring can be a major nuisance to the cosleeper due to its disruptive effect on sleep. Data suggests that snoring may be associated with an increased risk of cardiovascular morbidity [2-4].

Snoring may also be the symptom of a broad spectrum of obstructive respiratory abnormalities during sleep. This spectrum may range from the upper airway resistance syndrome (UARS) to overt obstructive sleep apnoea syndrome (OSAS). Both UARS and OSAS can be characterized by frequent arousal from sleep causing daytime sleepiness in certain individuals $[5,6]$.

The magnitude of this problem is amplified by the high prevalence of snoring in the general population. Various studies estimate a prevalence of $16-89 \%$ in the general population [7-9]. A recently published review [10] concerning the current knowledge of snoring and its health consequences, has emphasized that much of the uncertainty regarding direct health outcomes of snoring is in part related to the fact that most studies on the prevalence and health outcomes of snoring have not directly measured snoring.
* Dortmund Sleep Disorders Clinic and Research Center, Germany. **Stanford University Medical School, Sleep Disorders Clinic and Research Center, CA, USA. +University Hospital Bergmannsheil, Bochum, Department of Internal Medicine, Division of Pulmonary Medicine, Allergology and Sleep Medicine, Germany.

Correspondence: R.A. Stoohs Zentrum für Schlafmedizin \& Schlafstörungen

Hermannstraße 48-52

D-44263 Dortmund

Germany

Fax: 004923194113030

Keywords: Aging

instrumentation

sleep

sleep apnoea

snoring

Received: April 291997

Accepted after revision October 281997
To obtain quantitative data on the occurrence and natural history of snoring, a study comparing the direct measurement of snoring in a young college student population and an older population was conducted.

\section{Materials and methods}

\section{Study subjects}

The young population comprised a group of unselected Stanford University students from 1993 enrolled in a university course in human biology. An overnight sleep recording using an ambulatory recorder for the identification of sleep-disordered breathing $[11,12]$ was part of their participation in the class. The older population comprised unselected patients seen for routine medical checkups in a Veterans Administration (VA) medical center.

On the night of the recording, students and older subjects filled out a questionnaire consisting of 20 questions on patient demographics and daytime functioning, daytime sleep tendency, alertness, snoring, smoking history, and sleep quality. The questionnaire had been applied to more than 800 subjects prior to this study, and the questions concerning sleep-related items had been previously validated using polysomnography [13]. Expected 
responses varied depending on the questions from "yes" or "no" to "don't know" or answers on a five-point scale (range: $1=$ never to $5=$ =always). Three questions were used for the subjective report of snoring. The first question enquired about the occurrence of loud snoring, the second was geared to assess apnoeic snoring; subjects were asked about loud and irregular snoring and the third question asked for witnessed breathing pauses. Before filling out the questionnaire, each subject was given an explanation of the study procedure and signed, informed consent was obtained. Subjective daytime sleep tendency was assessed with a validated sleepiness scale, the Epworth Sleepiness Scale (ESS) [14].

The subjects were then tested overnight with a portable recording device: the MESAM4 (Medizintechnik für Arzt und Patient (MAP), Martinsried, Germany). This equipment has been previously validated for the presence or absence of apnoea and hypopnoea, and its specificity and sensitivity have been determined in a double-blind comparison with polysomnography [12]. The device is a microprocessor which continuously monitors four variables throughout the night: 1) cardiac frequency $\left(f_{\mathrm{C}}\right)$, monitored through a single-lead electrocardiogram (ECG) (modified V-2), with determination of R-R interval in milliseconds; 2) snoring sounds, monitored through an encapsulated electric subminiature microphone placed on the larynx; 3$)$ arterial oxygen saturation $\left(\mathrm{Sa}_{2} \mathrm{O}_{2}\right)$, measured by pulse oximetry through a flexible finger probe; 4) body position or movement, measured through a flat cylinder sensor placed on the lower part of the sternum.

Each monitor was prepared for recording using an IBM-compatible portable computer (Fry's Electronics, Palo Alto, CA). The start of the recording can be preset and is independent of electrode placement. This stage occurred in this study between 19:00 and 21:00 h.

Each individual also completed a sleep log in which to record lights-out and lights-on times, as well as behavioural awakenings and time spent awake. At morning awakening, subjects were asked to fill out a questionnaire rating sleep quality, sleep disturbances, and disturbances related to the equipment and another ESS. Subjects returned the equipment to a central location before 12:00 $\mathrm{h}$ the following day.

\section{Analysis}

Analyses were performed on an IBM-compatible computer through printed reports in full disclosure, generated by the MESAM software.

Previously collected datasets of MESAM4-recorded snoring and simultaneous polysomnographic recordings were re-evaluated [12]. During polysomnography, technicians were instructed to verify the presence of snoring when the microphone used in the polysomnographic recording indicated the presence of snoring. Using an intercom (Ritto, Harger, Germany), the presence of audible snoring was logged on the polysomnographic progress sheet. A double-blind comparison of time-synchronized snoring logs with MESAM4-recordings was conducted. A total of 174 instances of audible snoring were logged by technicians and compared to the presence or absence of snoring on the MESAM4 recording in a double-blind fashion. In the MESAM4 raw data either level of snoring (low or high) was considered as snoring. In 168 instances technician logs of snoring were verified in the MESAM4 snoring recording. In six instances (3.5\%), technician-logged snoring could not be verified by the MESAM4 raw data. Although technicians do not regularly assess the loudness of audible snoring we hypothesize that a check of audible snoring may not have been conducted or that the polysomnographic microphone may not have indicated the presence of snoring.
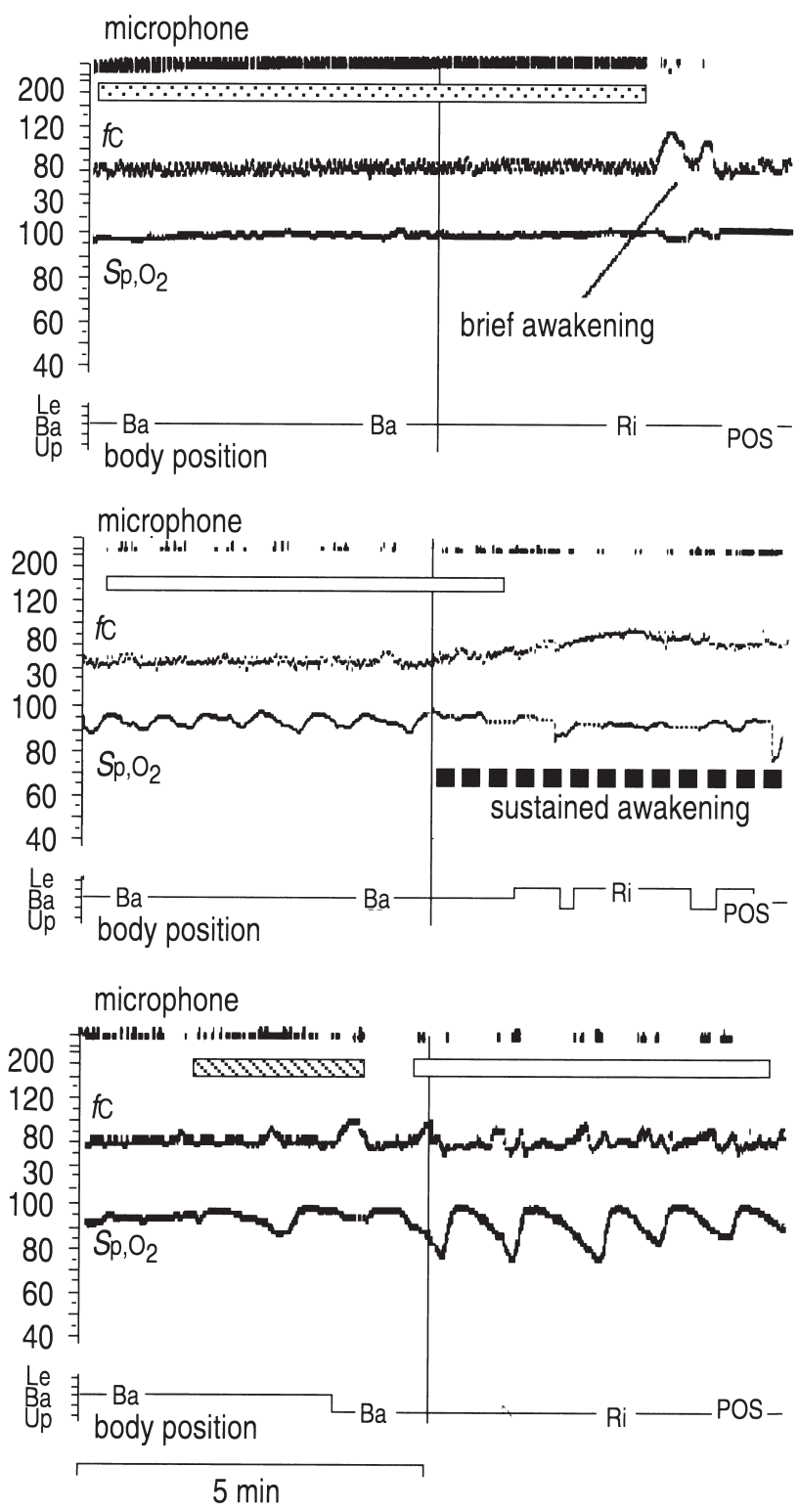

Fig. 1. - Determination of continuous apnoeic snoring and estimated sleep time using a representative MESAM4 hardcopy output. Each panel shows $10 \mathrm{~min}$ of recorded data. The continuous snoring index (CSI) is based on continuous snoring, i.e. each respiratory effort is marked as noise ( 5 ) as shown in the top panel. The apnoeic snoring index (ASI) is based on apnoeic/hypopnoeic snoring. Snoring appears in clusters separated by silent intervals as displayed in the middle panel (left side). Brief and sustained awakenings are determined based on cardiac frequency $\left(f_{\mathrm{C}}\right)$ acceleration. Nonapnoeic snoring.

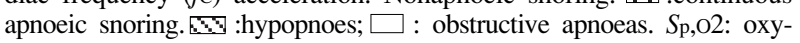
gen saturation measured by pulse oximetry. 
Snoring time was visually scored using a previously validated technique $[15,16]$.

Sleep times were estimated using sleep log information and by MESAM4 recorded parameters. Wake was scored when a sustained, significant increase in $f$ C occurred for at least $1 \mathrm{~min}$ and/or the body position sensor indicated upright or changed body position more than twice in a 5 min period. Sleep logs and sleep time scoring using the MESAM4 variables were used to calculate the estimated total sleep time (TSTe), the "continuous snoring index" (CSI) and the "apnoeic snoring index" (ASI). The pattern of apnoeic versus nonapnoeic snoring was visually identified. When each breath was associated with a noise pattern, snoring was defined as continuous. The MESAM4 system provides two different levels of sound intensity for the detection of snoring. Snoring was scored combining both intensity levels.

The MESAM4 system determines snoring in the frequency range $100-800 \mathrm{~Hz}$. The two different intensity thresholds correspond to approximately 40 and $50 \mathrm{~dB}$ (weighted average of sound intensity (A)) respectively.

When snoring occurred in clusters separated by silent intervals snoring was classified as apnoeic (fig. 1). The CSI and ASI were calculated by dividing the total time of visually identified snoring periods (continuous or apnoeic) by the determined TSTe in hours.

\section{Statistical analysis}

Results are expressed as mean \pm SD unless otherwise indicated. Log-corrected odds ratios (ORs) of being a snorer for subjects with a positive family history of snoring were compared to those with a negative family history of snoring [17] and 95\% confidence intervals (95\% CI) were used in the reporting of ORs. To determine potential interactions between selected sets of variables on dependent variables, multiple regression analysis and calculation of partial correlation coefficients was used. The Wilcoxon signed-rank matched pairs test for nonparametric data was used for statistic comparison. A pvalue less than 0.05 was considered to be significant. Nonparametric testing (Chi squared $\left(\chi^{2}\right)$ test) was used to evaluate the presence of statistically significant differences between groups for variables with nongaussian distribution.

\section{Results}

\section{Demographic data}

A total of 155 college students and 134 older subjects filled out detailed sleep logs prior to the overnight assessment of snoring. All subjects completed questionnaires on sleep habits and sleep disturbance. In the student group information concerning the family history of snoring was also obtained.

Of the total group $96 \%$ of students and $74 \%$ of older subjects were nonsmokers. The age of the student population averaged $19.9 \pm 2.6 \mathrm{yrs}$, and the older population averaged $64.1 \pm 9.1$ yrs $(\mathrm{p}<0.0001)$. The mean body mass index (BMI) for students was $22.3 \pm 3.2 \mathrm{~kg} \cdot \mathrm{m}^{-2}$ and
$29.3 \pm 5.3 \mathrm{~kg} \cdot \mathrm{m}^{-2}$ for older subjects $(\mathrm{p}<0.0001)$. The mean TSTe for students averaged $377.1 \pm 85.7$ versus $347.3 \pm 98.6$ min for older individuals $(\mathrm{p}<0.01)$. Self-reported alcohol consumption was available for students only. Of the student group 5\% reported the consumption of alcoholic beverages before bedtime.

\section{Occurrence of snoring in students and older subjects}

The average CSI for students was $22.6 \pm 21.9 \%$ compared to $15.3 \pm 14.1 \%$ for older subjects $(\mathrm{p}<0.05)$. The average ASIs were $0.2 \pm 0.6 \%$ versus $6.6 \pm 9.7 \%(\mathrm{p}<0.0001)$, respectively. Figure 2 shows the distribution of CSIs in students and older subjects. Using previously collected data on the subjective impairment of sleep to cosleepers, we defined an abnormal CSI at a cut-off level of $30 \%$ of sleep time snoring. We then calculated the occurrence of snoring above and below this $30 \%$ setpoint for the two subject populations. A significant difference was found between the two groups. Of the student group $30 \%$ presented a CSI $\geq 30 \%$ while in the older group only $17.2 \%$ presented a CSI $\geq 30 \%\left(\chi^{2}, \mathrm{p}<0.05\right)$. No significant difference was noted between students and older subjects at a CSI of $10 \%$.
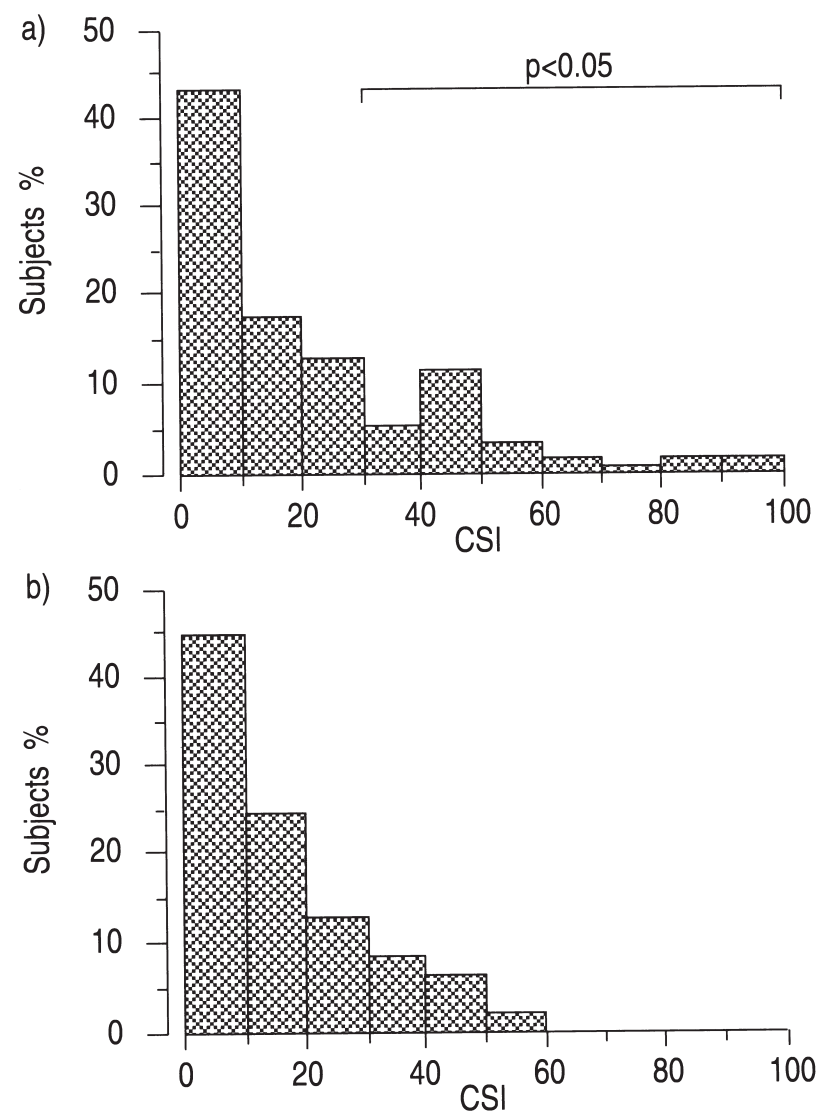

Fig. 2. - The percentage distribution of the continuous snoring index (CSI) in a) students and b) older subjects is similar in subjects in lower CSI categories (CSI 0-30\%). More students than older subjects presented CSI values in excess of $30 \%$. High CSI values in excess of $60 \%$ were seen in students only. 
Table 1. - Relationship between subjective self-reported snoring and the objectively-measured continuous snoring index

\begin{tabular}{lcc}
\hline $\begin{array}{l}\text { Subject } \\
\text { group }\end{array}$ & $\begin{array}{c}\text { Self-reported } \\
\text { snoring } \\
\%\end{array}$ & $\begin{array}{c}\text { Continuous } \\
\text { snoring index } \\
\%\end{array}$ \\
\hline Students & $1=51.7$ & $20.3 \pm 20.9$ \\
$(\mathrm{n}=155)$ & $2=30.9$ & $23.9 \pm 22.5$ \\
& $3=11.4$ & $23.7 \pm 18.1$ \\
& $4=3.4$ & $39.2 \pm 30.3$ \\
Older & $5=2.7$ & $45.7 \pm 33.3$ \\
$(\mathrm{n}=134)$ & $1=17.8$ & $15.6 \pm 14.5$ \\
& $2=17.8$ & $13.7 \pm 12.8$ \\
& $3=32.6$ & $15.5 \pm 15.4$ \\
& $4=22.5$ & $16.3 \pm 13.9$ \\
$5=9.3$ & $20.4 \pm 12.2$ \\
\hline
\end{tabular}

Students who reported that they never (score $=1$ ), rarely (score $=2$ ) or occasionally snore (score $=3$ ) showed similar measured continuous snoring index (CSI) values. Only students who reported that they often $($ score $=4)$ or always snored $($ score $=5$ ) showed a twofold increase in objectively measured CSI. This relationship between subjective and objective snoring could not be reproduced in the older population.

\section{Correlation between self-reported and objective snoring}

Table 1 shows the relationship between selfreported snoring and objectively-measured snoring in students and older subjects. The data shows a good correspondence between subjective self-reported snoring and objectively-measured snoring in students only. In students, the higher self-reported frequency of continuous snoring is associated with higher CSI values. There is no relationship between self-reported categories of continuous snoring frequency and objectively measured snoring in older individuals. When we combined regular and apnoeic snoring in the two subject populations, there was still the discrepancy between recorded snoring and self-reported snoring in the older subjects.

\section{Snoring and sleepiness}

Subjective sleepiness was assessed with validated tools: the ESS [14] and a five-point scale. A comparison between the ESS and the five-point scale was performed in 200 middle-aged subjects prior to this investigation. Good agreement exists between the ESS and the five-point scale $(\mathrm{r}=0.61 ; \mathrm{p}<0.0001)$. Students were divided into two groups depending on their sleepiness score on the ESS and the five-point scale. A score of 11 was the threshold used to define sleepiness, and answers to daytime sleepiness in the "often" or "always" categories of the five- point scale were considered as markers of significant daytime sleepiness. There was no difference in the percentage of younger subjects with sleepiness on the five-point scale compared to older subjects (22\% in younger subjects versus $23 \%$ in older subjects, $\left.\chi^{2}=0.04, p=N S\right)$. Sleepiness on the five-point scale neither correlated with the CSI in students nor in older subjects although a clear trend towards higher CSI values with increasing levels of daytime sleepiness was observed. Analysis of variance (ANOVA) between the self-reporting of daytime sleepiness and combined regular and apnoeic snoring in older individuals revealed
Table 2. - Relationship between ethnicity and the objective assessment of snoring

\begin{tabular}{lcll}
\hline Ethnic group & $\begin{array}{c}\text { Student } \\
\text { population } \\
\%\end{array}$ & $\begin{array}{c}\text { CSI } \\
\text { \% of TSTe }\end{array}$ & $\begin{array}{c}\text { BMI } \\
\mathrm{kg} \cdot \mathrm{m}^{-2}\end{array}$ \\
\hline African-American & 6.5 & $29.3 \pm 14.2$ & $25.2 \pm 4.6$ \\
American-Indian & 2.2 & $19.4 \pm 21.3$ & $23.6 \pm 2.1$ \\
Asian & 32.4 & $23.2 \pm 20.7$ & $21.4 \pm 2.6^{* * *}$ \\
Caucasian & 47.5 & $21.6 \pm 23.1$ & $22.2 \pm 2.4^{* *}$ \\
Hispanic & 9.4 & $23.0 \pm 25.5$ & $23.3 \pm 4.1$ \\
Pacific Islander & 1.4 & $14.9 \pm 5.5$ & $25.5 \pm 5.4^{*}$ \\
\hline
\end{tabular}

CSI: continuous snoring index; TSTe: estimated total sleep time; BMI: body mass index. ${ }^{*}, * *, * * *: \mathrm{p}<0.05, \mathrm{p}<0.01$, $\mathrm{p}<0.001$, compared to the African-American ethnic group.

significant differences in daytime sleepiness between subjects who indicated "never" snore and subjects who indicated "sometimes" $(\mathrm{p}<0.05)$, "often" $(\mathrm{p}<0.02)$ and "always"(p<0.0001) snore (ANOVA, $\mathrm{p}<0.001)$.

In students, an ESS score greater than 11 (51\% of students) was associated with a significantly higher cumulative sleep deficit assessed by ideal and actual sleep times in the questionnaire. These students had an average difference of $-0.50 \pm 1.12 \mathrm{~h}$ between actual and ideal sleep times when compared to students with an ESS score lower than 11 (49\% of students) $(\mathrm{p}<0.04)$.

The effect of gender, ethnicity, family history, and alcohol consumption on snoring in students

In the student group the effect of gender on the CSI was examined. No significant difference could be observed in the percentage of female versus male students for CSI $\geq 30 \%$. There was also no significant difference between males and female students in the self-reporting of snoring.

The potential effect of ethnicity on snoring in the student population was analysed. Table 2 shows the snoring data (CSI) and the BMI in the different ethnic groups. There was no statistically significant difference in the CSI between ethnic groups, although African-American students presented with the highest CSI. Significant differences in BMI were observed between the ethnic groups (table 2). AfricanAmerican students presented the highest BMI. Significant BMI differences between African-American students and Asian students $(\mathrm{p}<0.0005)$, between African-American students and Caucasian students ( $\mathrm{p}<0.005)$, and between AfricanAmerican students and Pacific Islander students $(p<0.04)$ could be demonstrated.

Of all students, $85 \%$ reported that at least one of their first-degree relatives were snorers. The corrected OR of objectively verified snoring using MESAM 4 for snoring individuals with first-degree relatives who had a CSI $\geq 30$ was $1.01(\mathrm{p}=\mathrm{NS})$. The corrected OR for self-reported snoreing of students with one snoring first-degree relative was $4.98(95 \%$ confidence interval $0.4-10.9)(\mathrm{p}<0.01)$.

\section{Discussion}

In this study, we were able to show that continuous snoring indicating partial obstruction during sleep was measured more frequently in a young population comprising undergraduate college students compared to an older 
population with an average age of 65 yrs. Furthermore, if data on the presence of snoring had been taken from subjective self-reporting using a questionnaire, opposite results would have been observed.

Various investigators have reported data on the occurrence of snoring and its potential cardiovascular complications using questionnaires. However, only few investigators have used objective measures of snoring in their studies. In a recent review article on this matter, HofFSTEIN [10] pointed out that no common standard has been developed for acoustic recordings during sleep. We would agree with Hoffstein that, in studies where sound recordings have been employed, the lack of an accepted standard makes comparison of the results difficult.

We chose a snoring assessment that has been widely used in epidemiological studies in Europe, the USA, and Australia [18-20]. This monitor has been validated previously by several investigators and shown to provide an accurate measure of the presence or absence of sleep-disordered breathing associated with apnoea and hypopnoea during sleep $[12,15]$. As these studies have not assessed the validity of the MESAM4 system in the detection of snoring we re-evaluated our original validation data and compared technician-reported snoring with MESAM4 recording of low and high level snoring. A high agreement between technician-logged, audible and MESAM4- recorded snoring was found. In about only $3 \%$ of the snoring validation data the technicians report of snoring could not be verified by the MESAM4 raw data. Although technicians do not regularly assess the loudness of audible snoring we hypothesize that the polysomnograpic microphone may not have indicated the presence of snoring with snoring below sensitivity levels of the microphone (approximately $40 \mathrm{~dB}(\mathrm{~A})$. Nevertheless, the high level of agreement between technician logs of snoring and MESAM4 snoring recording allows us to conclude that the quantitative acoustic measure of snoring sound, which we have termed the CSI, is an objective representation of the outcome measure under investigation in this study.

Analysis of the recorded acoustic measures of snoring, expressed as the average CSI showed that students had a significantly higher average snoring time during sleep than older subjects. The percentage of subjects in each age group who snored for more than $10 \%$ and $30 \%$ of the recording time was investigated. It was found that there was no difference at the cut-off level of $10 \%$ of recording time spent snoring between the groups. In both groups more than $50 \%$ of the subjects snored for more than $10 \%$ of the recording time $(55 \%$ of older subjects and $56 \%$ of students). However, when the number of individuals in each age group who snored for more than $30 \%$ of the recording time was compared a significant difference between students and older subjects was found. The cut-off of $30 \%$ of recording time spent snoring was chosen based on previous results using the MESAM4 recording equipment. At this level there was the highest agreement between the subjective perception of snoring by the bed partner and actual recorded snoring with the MESAM4 equipment. In the absence of objective measurements, prevalence data obtained by questionnaires only, must be interpreted with caution.

Analysis of the distribution of measured continuous snoring showed that a number of students snored for more than $60 \%$ of the recording time. None of the older subjects presented CSI values in excess of $60 \%$. This finding could be related to the fact that young individuals can develop a higher level of respiratory effort than older individuals [21]. The data also suggests that students may be able to sustain partial obstruction without developing an apnoeic snoring pattern in conjunction with complete upper airway obstruction: students had a significantly lower ASI than older subjects.

The significant decrease of measured snoring with age in the older group is in agreement with the overall lower CSI between the older group compared to the young student group. As expected, this significant relationship between age and measured snoring within the older group could not be reproduced within the young student group because of the narrow range of the variable age in this group. Thus, the relationship of age and measured snoring within and between the studied groups (young and older subjects) further strengthens the hypothesis that increasing age will result in less negative inspiratory effort generated during periods of increased upper airway resistance during sleep [21-23]. As younger subjects had lower BMIs than older subjects, another possible explanation could be that MESAM4 underestimates snoring, when there is evidence of increased neck fat distribution. However, our own unpublished results using measurements of neck skinfold thickness with a caliper do not support this hypothesis.

Although other factors such as a positive family history of snoring [24, 25], alcohol consumption [20, 26, 27], and partial sleep deprivation [28], have shown to be important modulators of snoring, none of these factors were significant predictors of the CSI in the young or older population.

There was a tendency towards a higher CSI in AfricanAmerican students. However, stratification of ethnic background reduced the number in each ethnic category substantially and reduced statistical power.

Analysis of the subjective snoring data showed that only $17.5 \%$ of the students reported to snore in the combined CSI categories of "sometimes", "often", and "always". In contrast, $64 \%$ of older subjects reported to snore in the same frequency categories. This finding conflicted with the findings in the objective measurements of snoring. Further analysis showed that there was a good agreement between subjective snoring frequency and objective measurement of snoring in students but not in older subjects. In fact, older subjects overestimated their subjective snoring in every frequency category. Thus, results of prevalence studies using a self-report of snoring frequency should be interpreted with care. In a recent investigation on the prevalence of snoring and breathing pauses in a telephone survey of a UK population sample, $23.1 \%$ of persons 15-24 yrs of age indicated a tendency to snore, closely matched the results for the CSI $\geq 30 \%$ in our student population [29]. The same UK study showed that a greater percentage of subjects aged $>65$ yrs indicated a higher self-reporting of snoring than the younger group. Based on our objective results, it is suggested that the subjective report of snoring in the older age group of the UK study may be an overestimation of the actual snoring frequency.

One possible explanation is recall bias: older individuals who no longer snore may have been told at some point in their lives that they snore. Furthermore, this 
age-related change in snoring can partially be explained by the physiological factors previously discussed. Another explanation for this change could be an age-related sleep stage redistribution and the resulting implications on upper airway resistance and respiratory muscle activity [30]. There is also the possibility that snoring may be perceived differently in different age groups based on a change in the sound frequency spectrum associated with age. Fiz et al. [31] have shown that a difference between apnoeic and nonapnoeic snoring sounds exists. The student population showed virtually no apnoeic snoring compared to the older subjects who spent $6 \%$ of their TSTe with an apnoeic snoring pattern [32].

The prevalence figures of self-reported snoring in our student population closely match the figures published by Hicks [33], although no demographic data are presented in this investigation of 749 college students.

We were not able to show a significant difference in the self-reporting and measurement of snoring between younger men and women. Hicks found that there was a difference between men and women college students in the self-reporting of snoring but concluded that this difference had a low strength [33].

Measured snoring did not have an impact on daytime sleepiness in either students or older subjects. Subjects with an ESS score greater than 11 did not present higher CSI values than subjects with ESS scores below 11 . Nevertheless, a surprisingly high number of students presented with ESS scores $>11$. This sleepy student group had a significantly higher sleep debt than students with ESS scores less than 11. This finding has been reported previously using a different methodology $[34,35]$.

Finally, a large number of college students reported that their first-degree relatives had a history of snoring. A positive family history of snoring did not increase the OR of measured snoring. However, there was a significant increase in the OR for perceived (subjective) snoring in subjects with a positive family history of snoring. This finding suggests, that the experience of having a first-degree relative who snores may cause a reporting bias in snoring.

We conclude that snoring is a highly prevalent phenomenon in younger and older adults. If studies of snoring in older subjects are performed using self-reporting questionnaires the data must be interpreted with caution. As we have shown, there is not always concordance between self-reported snoring and the objective measurement of snoring.

Acknowledgements: The authors would like to thank MAP, Martinsried, Germany for the generous loan of the MESAM4 equipment and E.J.L. Finlayson, E.V.A. Finlayson, and B.Y. Suh for editing the manuscript. We are indebted to the Stanford University students C. Oh, R. Chu, and P. Khatri for their valuable assistance in the data collection and analysis procedures.

\section{References}

1. Skatvedt O. Localization of site of obstruction in snorers and patients with obstructive sleep apnea syndrome: a comparison of fiberoptic nasopharyngoscopy and pre sure measurements. Acta Oto-Laryngologica 1993; 113 : 206-209.

2. Lugaresi E, Cirignotta F, Coccagna G, Piana C. Some epidemiological data on snoring and cardiocirculatory disturbances. Sleep 1980; 3: 221-224.

3. Palomaki H. Snoring and the risk of ischemic brain infarction. Stroke 1991; 22: 1021-1025.

4. Ketterer MW, Brymer J, Rhoads K, Kraft P, Kenyon L. Snoring and the severity of coronary artery disease in men. Psychosom Med 1994; 56: 232-236.

5. Stoobs R, Guilleminault C. Obstructive sleep apnea syndrome or abnormal upper airway resistance during sleep? J Clin Neurophysiol 1990; 7: 83-92.

6. Guilleminault C, Stoohs R, Clerk A, Cetel M, Maistros P. A cause of excessive daytime sleepiness. The upper airway resistance syndrome. Chest 1993; 104: 781-787.

7. Lugaresi E, Cirignotta F, Coccagna G, Piana C. Some epidemiological data on snoring and cardiocirculatory disturbances. Sleep 1980; 3: 221-224.

8. Gislason T, Benediktsdottir B, Bjornsson JK, Kjartansson G, Kjeld M, Kristbjarnarson H. Snoring, hypertension, and the sleep apnea syndrome. An epidemiologic survey of middleaged women. Chest 1993; 103: 1147-1151.

9. Gislason T, Taube A. Prevalence of sleep apnea syndrome-estimation by two stage sampling. Ups J Med Sci 1987; 92: 193-203.

10. Hoffstein V. Snoring. Chest 1996; 109: 201-222.

11. Standards of Practice Committee of the American Sleep Disorders Association. Practice parameters for the use of portable recording in the assessment of obstructive sleep apnea. Sleep 1994; 17: 372-377.

12. Stoohs R, Guilleminault C. MESAM 4: an ambulatory device for the detection of patients at risk for obstructive sleep apnea syndrome (OSAS). Chest 1992; 101: 1221-1227.

13. Stoohs R, Guilleminault C, Dement WC. A Model for Homebased Diagnosis of Sleep-Disordered Breathing: Establishing Pre-Test Probability. In: Biolac B, Paty J. Eds. Proceedings of the second international meeting on sleep disorders. Bordeaux, France, 1995; p 23.

14. Johns MW. A new method for measuring daytime sleepiness: the Epworth sleepiness scale. Sleep 1991; 14: 540-545.

15. Penzel T, Amend G, Meinzer K, Peter JH, von Wichert P. MESAM: a heart rate and snoring recorder for detection of obstructive sleep apnea. Sleep 1990; 13: 175-182.

16. Stoohs RA, Bingham LA, Itoi A, Guilleminault C, Dement WC. Sleep and sleep-disordered breathing in commercial longhaul truck drivers. Chest 1995; 107: 1275-1282.

17. Haldane JBS. The estimation and significance of the logarithm of a ratio of frequencies. Ann Hum Genet 1956; 2: 309- 311.

18. Ferini-Strambi L, Zucconi M, Palazzi S, Castronovo VO, Della Marca G, Smirne S. Snoring and nocturnal oxygen desaturations in an Italian middle-aged male population. Epidemiologic study with an ambulatory device. Chest 1994; 105: 1759-1764.

19. Stoohs RA, Bingham LA, Itoi A, Guilleminault C, Dement WC. Sleep and sleep-disordered breathing in commercial longhaul truck drivers. Chest 1995; 107: 1275-1282.

20. Bearpark H, Elliott L, Grunstein R, et al. Snoring and sleep apnea. A population study in Australian men. Am J Respir Crit Care Med 1995; 151: 1459-1465.

21. Shiomi T, Stoohs R, Guilleminault C. Aging, respiratory efforts during sleep, and pulsus paradoxus. Lung 1993; 171: 203-211. 
22. Smirne S, Iannaccone S, Ferini-Strambi L, Comola M Colombo E, Nemni R. Muscle fibre type and habitual snoring. Lancet 1991; 337: 597-599.

23. Shiomi T, Guilleminault C, Kayukawa Y, Wakida Y, Okamoto Y, Kobayashi T. A survey of habitual snoring in centenarians. $J$ Am Geriatr Soc 1997; 45: 84-86.

24. Redline S, Tosteson T, Tishler PV, Carskadon MAM, Millman RP. Studies in the genetics of obstructive sleep apnea. Familial aggregation of symptoms associated with sleep-related breathing disturbances. Am Rev Respir Dis 1992; 145: 440-444.

25. Douglas NJ, Luke M, Mathur R. Is the sleep apnoea/hypopnoea syndrome inherited? Thorax 1993; 48: 719-721.

26. Mitler MM, Dawson A, Henriksen SJ, Sobers M, Bloom FE. Bedtime ethanol increases resistance of upper airways and produces sleep apneas in asymptomatic snorers. Alcohol, Clin Exp Res 1988; 12: 801-805.

27. Scrima L, Hartman PG, Hiller FC. Effect of three alcohol doses on breathing during sleep in 30-49 year old nonobese snorers and nonsnorers. Alcohol, Clin Exp Res 1989; 13: 420-427.

28. Stoohs RA, Dement WC. Snoring and sleep-related breathing abnormality during partial sleep deprivation. New Engl J Med 1993; 328: 1279.
29. Ohayon MM, Guilleminault C, Priest RG, Caulet M. Snoring and breathing pauses during sleep: telephone interview survey of a United Kingdom population sample. BMJ 1997; 314: 860-863.

30. Henke KG, Dempsey JA, Badr MS, Kowitz JM, Skatrud JB. Effect of sleep-induced increases in upper airway resistance on respiratory muscle activity. $J$ Appl Physiol 1991; 70: 158-168.

31. Fiz JA, Abad J, Jane R, et al. Acoustic analysis of snoring sound in patients with simple snoring and obstructive sleep apnoea. Eur Respir J 1996; 9: 2365-2370.

32. Liistro G, Stanescu DC, Veriter C, Rodenstein D. Pattern of snoring in obstructive sleep apnea patients and in heavy snorers. Sleep 1991; 14: 517-525.

33. Hicks RA. Incidence and severity of self-reported snoring in male and female college students. Percept Mot Skills 1992; 74: 770.

34. Anders TF, Carskadon MA, Dement WC. Sleep and sleepiness in children and adolescents. Pediatr Clin North Am 1980; 27: 29-43.

35. Carskadon MA, Harvey K, Dement WC. Sleep loss in young adolescents. Sleep 1981; 4: 299-312. 